ISSN 2466-2232

Online ISSN 2466-2100

\title{
$\mathrm{Sn}-\mathrm{xSb}$ 계 솔더의 전기화학적 부식 특성
}

\author{
손준혁* · 유동열* · 고용호* · 방정환,+ \\ *한국생산기술연구원 마이크로조이닝센터
}

\section{A Study on the Electrochemical Corrosion Property of Sn-xSb Solder Alloy}

\author{
Junhyuk Son*, Dong-Yurl Yu*, Yong-Ho Ko*, and Junghwan Bang*, \\ *Welding and Joining R\&D Group, Korea Institute of Industrial Technology (KITECH), \\ Incheon, 21999, Korea
}

†Corresponding author : nova75@kitech.re.kr

(Received June 6, 2018 ; Revised June 11, 2018 ; Accepted June 14, 2018)

\begin{abstract}
In this study, the electrochemical corrosion property was measured by increasing $\mathrm{Sb}$ contents. The corrosion property of Sn-5Sb, Sn- $8 \mathrm{Sb}$, Sn-10Sb, Sn-8Sb-3Ag solder alloys was measured using polarization test. The polarization curves were measured in 3.5 wt. $\% \mathrm{NaCl}$ solution of $25{ }^{\circ} \mathrm{C} . \mathrm{Ag} / \mathrm{AgCl}$ and platinum were used by reference electrode and counter electrode, respectively. Corrosion potential $\left(\mathrm{E}_{\text {corr }}\right)$, corrosion current density ( $\left.\mathrm{I}_{\text {corr }}\right)$ and linear polarization resistance (LPR, $\mathrm{R}_{\mathrm{p}}$ ) were estimated from the anodic and cathodic tafel lines. SnSb IMC was more diffused in the $\beta$-Sn structure by increasing $\mathrm{Sb}$ contents. Also, $\mathrm{SnSb}$ and $\mathrm{Ag}_{3} \mathrm{Sn} \mathrm{IMC}$ was diffused in the $\beta-\mathrm{Sn}$ structure at $\mathrm{Sn}-8 \mathrm{Sb}-3 \mathrm{Ag}$ solder alloy. The corrosion potential $\left(\mathrm{E}_{\text {corr }}\right)$ and corrosion current density $\left(\mathrm{I}_{\text {corr }}\right)$ was increased by increasing $\mathrm{Sb}$ contents. But, the linear polarization resistance (LPR) was decreased by increasing $\mathrm{Sb}$ contents.
\end{abstract}

Key Words : Sn-Sb solder, Electrochemical corrosion, Corrosion potential, Corrosion current density, Linear polarization resistance

1. 서 론

전력반도체(Power semiconductor)는 전력용 파워 스위칭 소자(Power switching device)와 제어 IC로 구성되어 전자기기에 주입되는 전력을 변환 및 분배, 관리하는 역할을 하는 반도체로, 일반 반도체에 비해 고 신뢰성이 요구되며, 하이브리드 자동차, 전기 자동 차 등의 개발로 그 수요가 증가하고 있다. 전력반도체 모듈은 전력반도체 소자 및 패키징 소재의 모듈 집적화 설계 기술, 제조 공정기술, 특성시험 및 신뢰성 평가 등의 주요 기술을 통해 구현되는 것으로, 특히 친환경 자동차인 하이브리드 자동차 및 전기자동차에 적용되는 전력모듈은 고온 및 진동 등의 열악한 환경에서 동작되 기 때문에 높은 신뢰성이 요구된다 ${ }^{1,2)}$. 전력반도체용 솔더로 $\mathrm{Sn}-\mathrm{Pb}$ 계 솔더가 주로 사용되었으나, 친환경 규
제인 자동차 폐차처리지침(ELV, End of Life Vehicle) 법규로 인해 자동차용 전력 반도체에 대한 무연솔더 적 용이 진행되고 있다.4). 이를 대체할 솔더 후보로 비교 적 젖음성 및 크립 특성이 우수한 $\mathrm{Sn}-\mathrm{Sb}$ 계 솔더가 거 론되고 있으며, 고온, 고습 및 진동 등의 사용 환경에 따른 신뢰성 연구가 진행 되고 있다 ${ }^{5,6)}$. 하지만 솔더링 공정 중 사용되는 플럭스나 세척공정 또는 대기 중의 염분, 습기 등의 사용환경에 대한 솔더 접합부의 부식 신뢰성에 관한 연구는 미비한 실정이다 ${ }^{7)}$. 내식성을 평 가하기 위한 일반적인 부식 시험방법으로는 염수분무시 험법(Salt Spray Test)과 CASS(Copper Accelerated Acetic Acid Salt Spray)시험, 전기화학적 분극시험방 법이 있다. 하지만 부식 면적률에 의한 Rating Number 로 솔더의 내식성을 평가는 염수분무시험법 및 CASS 시험법은 시험 검사자의 주관이 개입될 여지가 많아, 시험결과에 대한 객관적인 정량화가 쉽지 않다는 단점

Journal of Welding and Joining, Vol.36 No.3(2018) pp78-82

https://doi.org/10.5781/JWJ.2018.36.3.12 


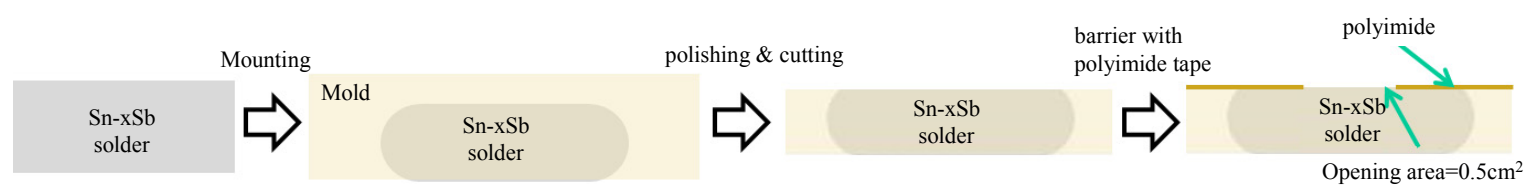

Fig. 1 Schematic of fabricated of test sample

이 있다 ${ }^{8,9)}$.

이에 본 연구에서는, 단기간에 솔더의 내식성을 정량 적으로 평가할 수 있다는 장점을 가진 전기화학적 부식 시험 방법을 사용하여 $\mathrm{Sb}$ 함량에 따른 $\mathrm{Sn}-\mathrm{xSb}$ 계 솔더 의 부식특성을 비교 평가하였다. 이를 기초로 $\mathrm{Sn}-\mathrm{xSb}$ 계 솔더의 전기화학적 부식특성을 통해 전력반도체용 고온 솔더의 적합여부를 비교, 평가하였다.

\section{2. 실험방법}

\section{1 시험 시편 제작}

본 연구에서는 $\mathrm{Sb}$ 함량에 따른 솔더의 전기화학적 특성을 분석하고자 $\mathrm{Sn}-5 \mathrm{Sb}, \mathrm{Sn}-8 \mathrm{Sb}, \mathrm{Sn}-10 \mathrm{Sb}, \mathrm{Sn}^{-}$ $8 \mathrm{Sb}-3 \mathrm{Ag}$ 조성의 솔더를 사용하였다. 각각의 솔더를 에폭시 수지로 마운팅 후, 연마지와 알루미나 파우더를 사용하여 기계적 연마를 실시하였다. 그 후, 솔더를 $0.5 \mathrm{~cm}^{2}$ 면적만 노출되게 시편을 제작하였다. 시험 시 편의 제작 모식도를 Fig. 1 에 나타내었다.

\section{2 미세구조 분석}

$\mathrm{Sb}$ 함량에 따른 $\mathrm{Sn}-\mathrm{xSb}$ 계 솔더의 미세구조 및 금속 간화합물의 형상을 관찰하기 위해 $\mathrm{EPMA}$ (Electron Probe Micro Analyzer)를 사용하여 관찰하였으며, $\mathrm{XRD}(\mathrm{X}$-ray diffraction)를 사용하여 형성된 금속간화 합물의 종류를 분석하였다.

\section{3 분극 시험}

$\mathrm{Sb}$ 함량에 따른 부식 특성을 측정하기 위해 HOKUTO $\mathrm{DENKO}$ 社의 HZ-7000 모델을 사용하였으며, $25{ }^{\circ} \mathrm{C}$, 3.5 wt. $\% 1$ mole 농도의 $\mathrm{NaCl}$ 용액에서 전기화학 적 분극 시험을 진행하였다. 측정에 사용된 표준전극으 로 은/염화은 $(\mathrm{Ag} / \mathrm{AgCl})$ 전극을 사용하였으며, 분극 특 성은 $-1200 \mathrm{mV}$ 에서 $+600 \mathrm{mV}$ 범위의 전위에서 관 찰하였다. 시험시편에 전위를 인가한 후, 발생되는 전 류의 일반적인 분극 곡선 그래프를 Fig. 2에 나타내었 다. $\mathrm{AB}$ 및 $\mathrm{BF}$ 는 각각 음극 및 양극 분극 곡선을 나타 낸다. 타펠 외삽법(Tafel extrapolation)을 사용하여 양극 및 음극 분극 곡선에 접선을 구하였다. 두 접선의 교점 $(\mathrm{C})$ 을 부식전류밀도 $\left(\mathrm{I}_{\mathrm{corr}}\right)$ 라 하며, 이때의 전위 값

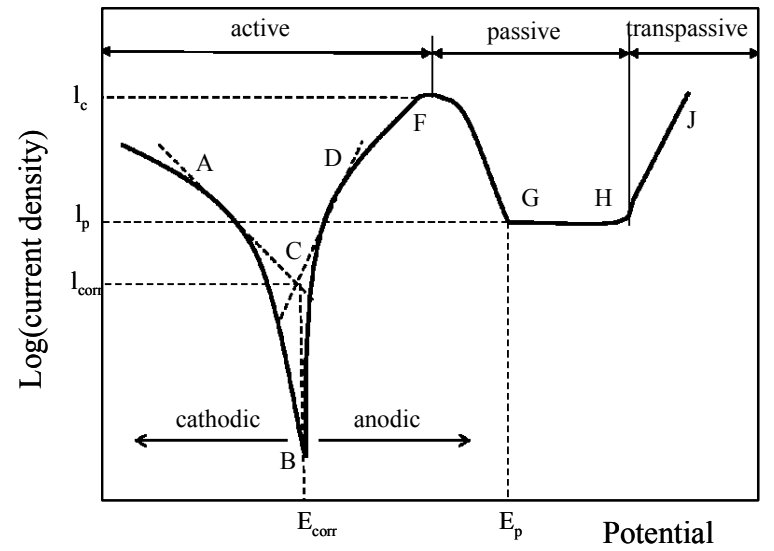

Fig. 2 Schematic polarization curve of passivable metals

을 부식전위 $\left(\mathrm{E}_{\mathrm{corr}}\right)$ 라고 한다. 전류밀도가 최대가 되는 지점 $(\mathrm{F})$ 의 전위를 부동태화 전위 $\left(\mathrm{E}_{\mathrm{p}}\right)$, 전류를 부동태 화 임계전류 $\left(\mathrm{I}_{\mathrm{c}}\right)$ 라 한다. $\mathrm{FG}$ 영역에서 복합 산화물의 생 성으로 부식 전류밀도가 감소되며, 점 $\mathrm{H}$ 는 부동태영역 전류밀도 $\left(\mathrm{I}_{\mathrm{p}}\right)$ 라고 한다. 그 후, 산화물의 파괴가 시작될 때까지 비교적 안정적으로 유지된다. 이를 기반으로 $\mathrm{Sn}-$ $\mathrm{xSb}$ 계 솔더의 $\mathrm{E}_{\mathrm{corr}}, \mathrm{I}_{\mathrm{corr}}, \mathrm{E}_{\mathrm{p}}, \mathrm{I}_{\mathrm{c}}$ 및 $\mathrm{R}_{\mathrm{p}}$ 값을 측정하였 다 ${ }^{10)}$.

\section{3. 결과 및 고찰}

\section{1 미세구조 관찰}

$\mathrm{Sn}-\mathrm{xSb}$ 솔더의 $\mathrm{Sb}$ 함량에 따른 미세구조를 관찰한 EPMA mapping 이미지를 Fig. 3에 나타내었다. (a), (b), (c) 에서는 $\beta-\mathrm{Sn}$ 조직 내에 수 $\mathrm{um}$ 이하의 $\mathrm{SnSb}$ 금속간화합물이 미세하게 분산되어 있으며, (d) 는 $\beta-\mathrm{Sn}$ 조직 내에 $\mathrm{SnSb}, \mathrm{Ag}_{3} \mathrm{Sn}$ 금속간화합물이 분산되어 있다.

$\mathrm{Sb}$ 함량에 따른 석출상 및 금속간화합물의 XRD 분 석 결과를 Fig. 4에 나타내었다. $\mathrm{Sn}-(5,8,10) \mathrm{Sb}$ 솔 더의 경우 $\mathrm{Sn}, \mathrm{SnSb}$ 금속간화합물이 검출 되었으며, $\mathrm{SnSb}$ 화합물의 경우 $\mathrm{Sb}$ 의 함량이 높아질수록 $\mathrm{SnSb}$ 금속간화합물이 증가하였다. $\mathrm{Sn}-8 \mathrm{Sb}-3 \mathrm{Ag}$ 솔더는 $\mathrm{Sn}$, $\mathrm{SnSb}$ 외에 $\mathrm{Ag}_{3} \mathrm{Sn}$ 금속간화합물이 검출되었다.

3.2 분극 특성 비교

$-1200 \mathrm{mV} \sim+600 \mathrm{mV}$ 전위 사이에서 측정된 $\mathrm{Sn}^{-}$ 

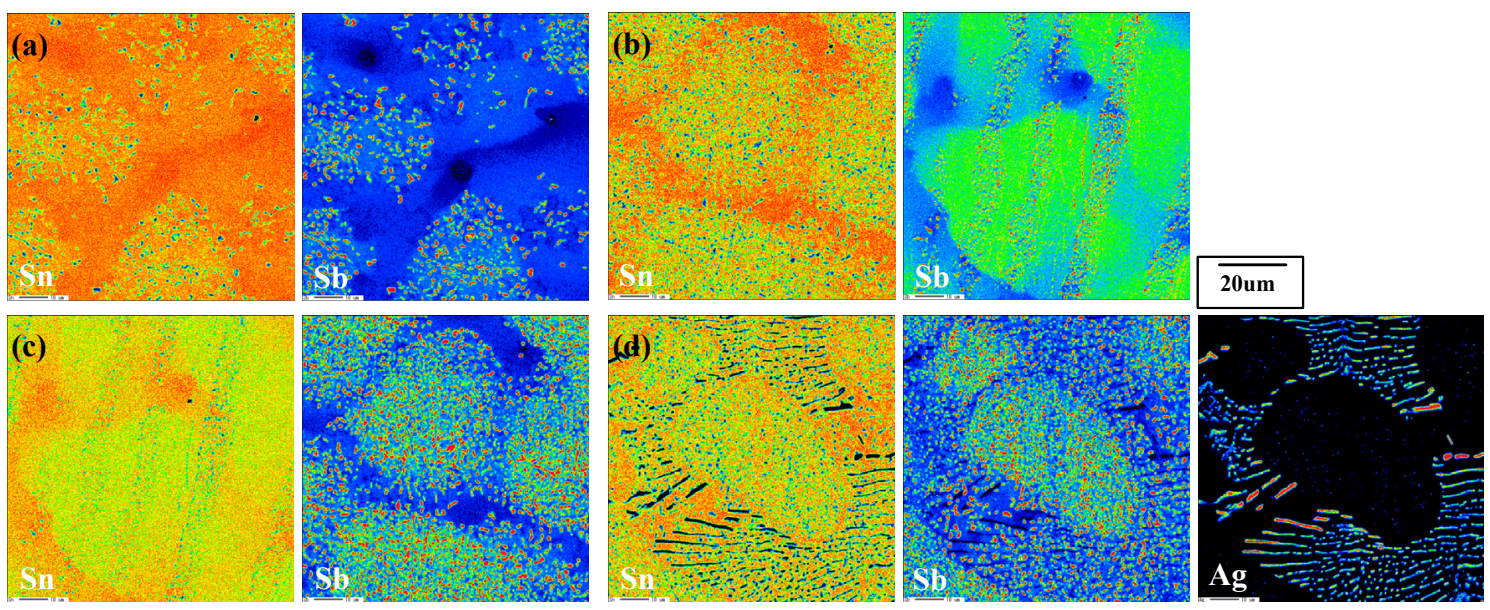

Fig. 3 EPMA mapping images of various solders:(a) Sn-5Sb (b) Sn-8Sb (c) Sn-10Sb (d) Sn-8Sb-3Ag

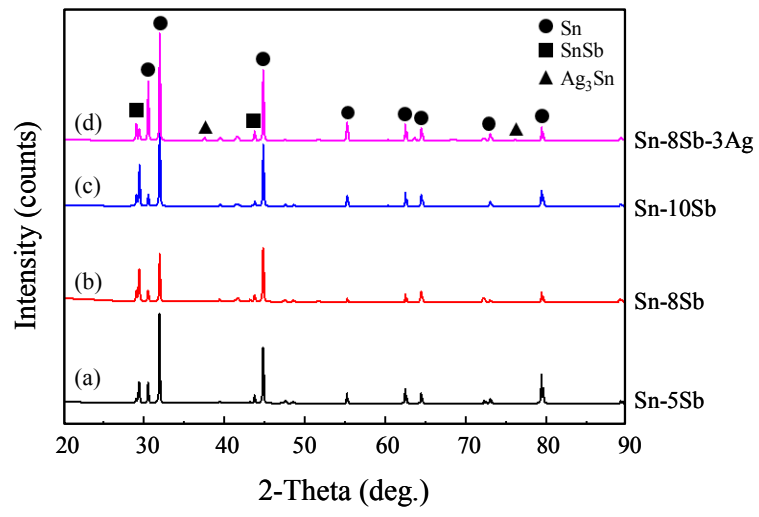

Fig. 4 XRD patterns of various solders:(a) $\mathrm{Sn}-5 \mathrm{Sb}$ (b) $\mathrm{Sn}-8 \mathrm{Sb}$ (c) Sn-10Sb (d) Sn-8Sb-3Ag

$\mathrm{xSb}$ 솔더의 음극 및 양극 분극 곡선을 Fig. 5 에 나타 내었다. 이때의 분극 곡선 결과를 통하여 측정된 $\beta_{\mathrm{a}}, \beta_{\mathrm{b}}$, $\mathrm{E}_{\text {corr }}, \mathrm{I}_{\text {corr }}, \mathrm{E}_{\mathrm{p}}, \mathrm{I}_{\mathrm{c}}$ 값을 Table 1 에 나타내었다. $\mathrm{E}_{\text {corr }}$ 의 경우 $\mathrm{Sn}-5 \mathrm{Sb}$ 는 $-506 \mathrm{mV}, \mathrm{Sn}-8 \mathrm{Sb}$ 는 $-477 \mathrm{mV}, \mathrm{Sn}^{-}$ $10 \mathrm{Sb}$ 는 $-429 \mathrm{mV}, \mathrm{Sn}-8 \mathrm{Sb}-3 \mathrm{Ag}$ 는 $-418 \mathrm{mV}$ 로 측정되 었으며, 솔더 조성에 따른 $\mathrm{E}_{\mathrm{corr}}$ 그래프를 Fig. 6 에 나 타내었다. $\mathrm{Sb}$ 의 함량이 증가할수록 $\mathrm{E}_{\mathrm{corr}}$ 이 높게 측정 되는 이유는 $\mathrm{Sn}^{-x} \mathrm{Sb}$ 계 솔더에 존재하는 $\mathrm{Sn}$ 이 가장 먼 저 부식이 진행되기 때문으로 사료된다. 이는 표준 전 극 전위에 따라 $\mathrm{Sb}, \mathrm{Ag}$ 보다 $\mathrm{Sn}$ 값이 상대적으로 낮

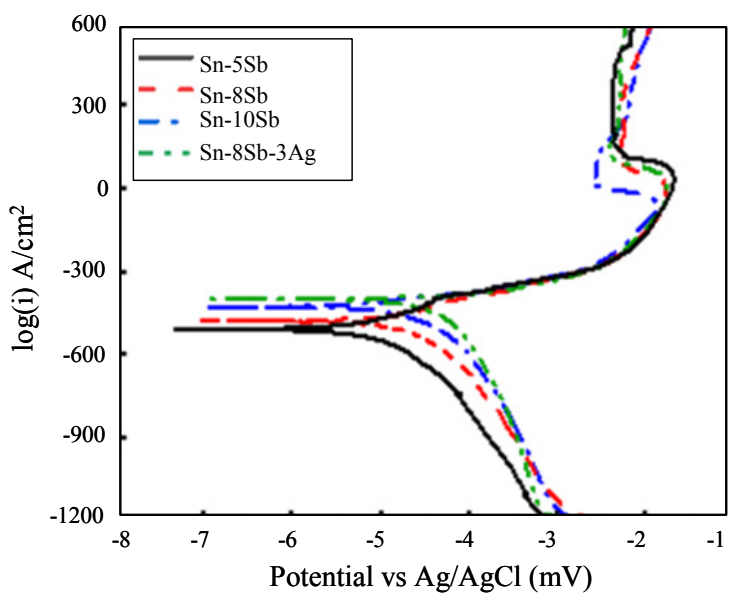

Fig 5 Polarization curves of Sn-xSb solder alloys in 3.5 wt.\% $\mathrm{NaCl}$ solution

아 $\mathrm{Sn}$ 의 함량이 높은 $\mathrm{Sn}-5 \mathrm{Sb}$ 솔더의 $\mathrm{E}_{\mathrm{corr}}$ 이 가장 낮게 측정되었다. 표준 전극 전위를 Table 2 에 나타내었다 ${ }^{11)}$.

기존 문헌에 따르면 선형분극저항 $\left(\mathrm{R}_{\mathrm{p}}\right)$ 은 전극표면에 서의 부식속도와 반비례적 관계가 있다고 보고되고 있 으며, Stern-Geary 식을 사용하여 $\mathrm{R}_{\mathrm{p}}$ 를 구하였다 ${ }^{12,13)}$. 이때의 $\beta_{a}$ 와 $\beta_{c}$ 는 양극 및 음극의 타펠 기울기이며, 솔더 조성에 따라 계산된 $\mathrm{R}_{\mathrm{p}}$ 를 Fig. 7 에 나타내었다. $\mathrm{Sn}-5 \mathrm{Sb}$ 는 $5.10 \times 10^{3} \Omega \cdot \mathrm{cm}^{2}, \mathrm{Sn}-8 \mathrm{Sb}$ 는 $2.79 \times 10^{3}$

Table 1 Experimental data of the $\mathrm{Sn}-\mathrm{xSb}$ solders alloys under polarization in $3.5 \% \mathrm{NaCl}$ solution

\begin{tabular}{|c|c|c|c|c|c|c|c|}
\hline Solder & $\begin{array}{c}\beta_{\mathrm{a}} \\
(\mathrm{mV} / \mathrm{dec})\end{array}$ & $\begin{array}{c}\beta_{\mathrm{c}} \\
(\mathrm{mV} / \mathrm{dec})\end{array}$ & $\begin{array}{c}\mathrm{E}_{\text {corr }} \\
(\mathrm{mV})\end{array}$ & $\begin{array}{c}\mathrm{I}_{\text {corr }} \\
\left(\mathrm{uA} / \mathrm{cm}^{2}\right)\end{array}$ & $\begin{array}{c}\mathrm{R}_{\mathrm{p}} \\
\left(\Omega \cdot \mathrm{cm}^{2}\right)\end{array}$ & $\begin{array}{c}\mathrm{E}_{\mathrm{p}} \\
(\mathrm{mV})\end{array}$ & $\begin{array}{c}\mathrm{I}_{\mathrm{c}} \\
\left(\mathrm{A} / \mathrm{cm}^{2}\right)\end{array}$ \\
\hline $\mathrm{Sn}-5 \mathrm{Sb}$ & 106.99 & 130.41 & -506 & 5.01 & $5.10 \times 103$ & 34.31 & 0.0214 \\
\hline $\mathrm{Sn}-8 \mathrm{Sb}$ & 83.62 & 121.18 & -477 & 7.74 & $2.79 \times 103$ & -12.16 & 0.018 \\
\hline $\mathrm{Sn}-10 \mathrm{Sb}$ & 31.22 & 26.66 & -429 & 7.96 & $2.32 \times 103$ & -71.15 & 1.48 \\
\hline $\mathrm{Sn}-8 \mathrm{Sb}-3 \mathrm{Ag}$ & 35.68 & 133.23 & -418 & 9.19 & $1.33 \times 103$ & -1.16 & 0.017 \\
\hline
\end{tabular}




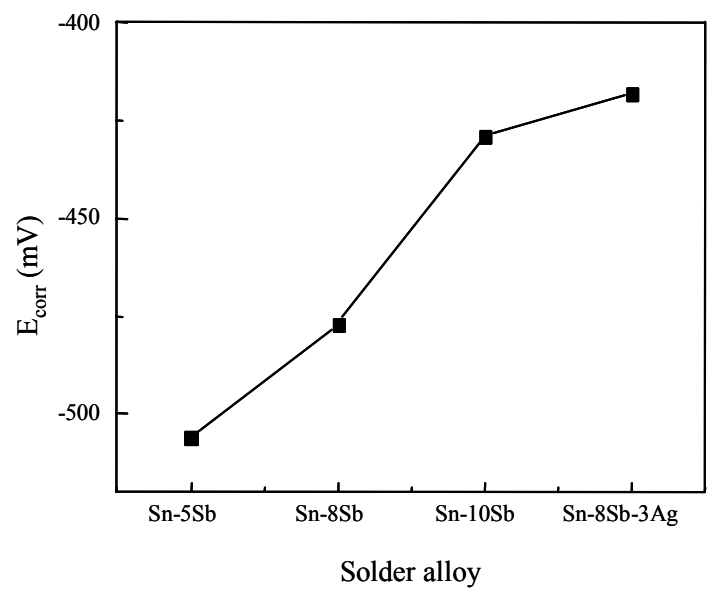

Fig. $6 \mathrm{E}_{\text {corr }}$ value during polarization of the $\mathrm{Sn}-\mathrm{xSb}$ solder alloys in $3.5 \% \mathrm{NaCl}$ solution

Table 2 Standard electrode potentials of $\mathrm{Sn}, \mathrm{Sb}$, and $\mathrm{Ag}$

\begin{tabular}{|c|c|}
\hline Electrode reaction & $\begin{array}{c}\text { Standard potential at } 25^{\circ} \mathrm{C} \\
\text { (V vs SHE) }\end{array}$ \\
\hline $\mathrm{Sn}^{2+}+2 \mathrm{e}^{-} \rightarrow \mathrm{Sn}$ & -0.136 \\
\hline $\mathrm{Sb}^{3+}+3 \mathrm{e}^{-} \rightarrow \mathrm{Sb}$ & 0.10 \\
\hline $\mathrm{Ag}^{+}+\mathrm{e}^{-} \rightarrow \mathrm{Ag}$ & 0.799 \\
\hline
\end{tabular}

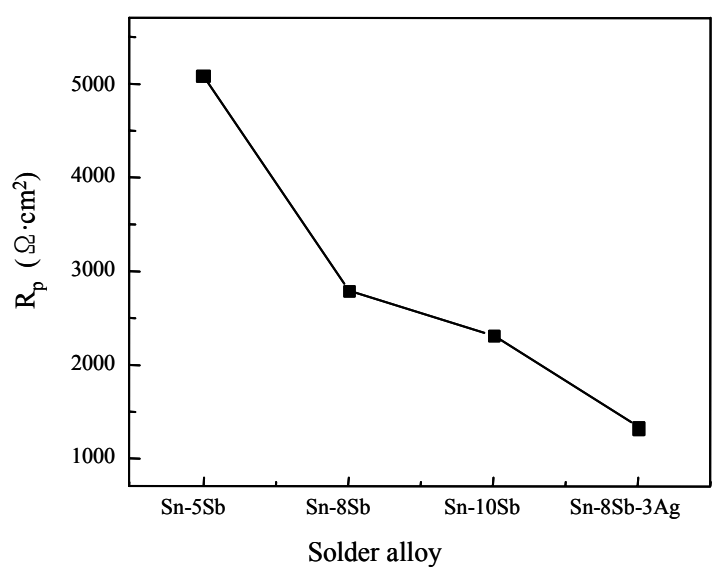

Fig. $7 \mathrm{R}_{\mathrm{p}}$ value during polarization of the $\mathrm{Sn}-\mathrm{xSb}$ solder alloys in $3.5 \% \mathrm{NaCl}$ solution

$\Omega \cdot \mathrm{cm}^{2}, \mathrm{Sn}-10 \mathrm{Sb}$ 는 $2.32 \times 10^{3} \Omega \cdot \mathrm{cm}^{2}, \mathrm{Sn}-8 \mathrm{Sb}-3 \mathrm{Ag}$ 는 $1.33 \times 10^{3} \Omega \cdot \mathrm{cm}^{2}$ 의 값을 구하였다.

기존 연구에 따르면, 솔더 내부의 금속간화합물과 $\mathrm{Sn}$ 사이의 전위차에 의한 갈바닉 부식의 효과로 금속간화 합물이 증가함에 따라 부식저항이 낮게 측정된다고 보고 되고 있다 ${ }^{14,15)}$. 따라서 $\mathrm{Sb}$ 함량이 증가함에 따라 $\mathrm{SnSb}$ 금속간화합물이 증가하게 되어 $\mathrm{R}_{\mathrm{p}}$ 가 낮게 측정된 것으 로 사료된다 ${ }^{16)}$. 또한, $\mathrm{Sn}-8 \mathrm{Sb}-3 \mathrm{Ag}$ 솔더에서는 $\mathrm{SnSb}$ 및 $\mathrm{Ag}_{3} \mathrm{Sn}$ 금속간화합물의 생성에 따른 $\mathrm{R}_{\mathrm{p}}$ 가 낮게 측 정된 것으로 사료된다.

\section{4. 결 론}

$\mathrm{Sb}$ 함량에 따른 $\mathrm{Sn}-\mathrm{xSb}$ 계 솔더의 $25^{\circ} \mathrm{C}, 3.5 \mathrm{wt} \%$ $\mathrm{NaCl}$ 용액에서 부식 시험을 진행하였다. 이를 기초로 $\mathrm{Sn}-\mathrm{xSb}$ 계 솔더의 전기화학적 부식특성 및 선형분극저 항 $\left(\mathrm{R}_{\mathrm{P}}\right)$ 을 비교하였다. 이러한 결과를 통해 다음과 같은 결론을 얻었다.

1) $\mathrm{Sn}^{-x} \mathrm{Sb}$ 계 솔더의 미세구조 관찰결과, $\mathrm{Sn}^{-}(5,8$, 10) $\mathrm{Sb}$ 솔더의 경우 $\beta-\mathrm{Sn}$ 조직 내에 수 um 이하의 $\mathrm{SnSb}$ 금속간화합물이 미세하게 분산되어 있으며, $\mathrm{Sb}$ 의 함량 이 높아질수록 $\mathrm{SnSb}$ 금속간화합물의 양은 증가하였다. $\mathrm{Sn}-8 \mathrm{Sb}-3 \mathrm{Ag}$ 솔더의 경우 $\beta-\mathrm{Sn}$ 조직 내에 $\mathrm{SnSb}$, $\mathrm{Ag}_{3} \mathrm{Sn}$ 금속간화합물이 분산되었다.

2) 부식전위 비교 결과, $\mathrm{Sb}$ 의 함량이 증가할수록 부 식전위가 높게 측정되었다. $\mathrm{Sb}$ 의 함량이 증가할수록 부 식전위가 높게 측정되는 이유는 표준 전극 전위에 따라 $\mathrm{Sb}, \mathrm{Ag}$ 보다 $\mathrm{Sn}$ 값이 상대적으로 낮아 $\mathrm{Sn}$ 의 함량이 높은 $\mathrm{Sn}-5 \mathrm{Sb}$ 솔더의 부식전위가 가장 낮게 측정된 것 으로 사료된다.

3) 선형분극저항 비교 결과, $\mathrm{Sb}$ 와 $\mathrm{Ag}$ 의 함량이 증가할 수록, 선형분극저항이 낮게 측정되었다. $\mathrm{SnSb}$ 및 $\mathrm{Ag}_{3} \mathrm{Sn}$ 금속간화합물의 증가에 따른 $\mathrm{Sn}$ 과 금속간화합물의 전 위차에 의한 갈바닉 부식의 효과로 부식저항이 낮게 측 정된 것으로 사료된다.

\section{후기}

본 연구는 산업통상자원부 글로벌전문기술개발사업의 지원으로 수행되었습니다.

ORCID : Junhyuk Son: https://orcid.org/0000-0002-8866-835X ORCID : Junghwan Bang: https://orcid.org/0000-0002-0226-9076

\section{References}

1. J. W. Yoon, J. H. Bang, Y. H. Ko, S. H. Yoo, J. K. Kim, C. W. Lee, Power Module Packaging Technology with Extended Reliability for Electric Vehicle Applications, J. Microelectron. Packag. Soc. 21(4) (2014), 1-13 https://doi.org/ 10.6117/kmeps.2014.21.4.001

2. J. H. Bang, D. Y. Yu, Y. H. Ko, J. W. Yoon, C. W. Lee, Leadfree Solder for Automotive Electronics and Reliability Evaluation of Solder Joint, Journal of Welding and Joining, 34(1) (2016), 26-34

https://doi.org/10.5781/JWJ.2016.34.1.26

3. J. Biela, M. Schweizer, S. Waffler, Johann W. Kolar, SiC versus Si-Evaluation of Potentials for Performance Improvement of Inverter and DC-DC Converter Systems 
by $\mathrm{SiC}$ Power Semiconductors, IEEE Transactions on Industrial Electronics, 58(7) (2011), 2872-2882 https://doi.org/ 10.1109/TIE.2010.2072896

4. W. M. Choi, H. G. Ahn, The Switching Characteristic and Efficiency of New Generation SiC MOSFET, Journal of the Korea Institute of Information and Communication Engineering, 21(2) (2017), 353-360 https://doi.org/10.6109/jkiice.2017.21.2.353

5. RODNEY J. MCCABE, MORRIS E. FINE, Creep of Tin, Sb Solution Strengthened Tin, and SbSn PrecipitateStrengthened Tin, Metallurgical and Materials Transactions, 33A, (2002) 1531-1539

6. J. H. Son, M. K. Kim, D. Y. Yu, Y. H. Ko, J. W. Yoon, C. W. Lee, Y. B. Park, J. H. Bang, Thermal Aging Characteristics of $\mathrm{Sn}-\mathrm{xSb}$ Solder for Automotive Power Module, Journal of Welding and Joining, 35(5) (2017), 38-47 https://doi.org/10.5781/JWJ.2017.35.5.6

7. W. S. Hong, K. B. Kim, Tafel Characteristics by Electrochemical Reaction of $\mathrm{SnAgCu} \mathrm{Pb-Free} \mathrm{Solder,} \mathrm{Korea}$ Journal of Materials Research, 15(8) (2005), 536-542

8. BO LIU, TAE-KYU LEE, KUO-CHUAN LIU, Impact of $5 \% \mathrm{NaCl}$ Salt Spray Pretreatment on the Long-Term Reliability of Wafer-Level Packages with $\mathrm{Sn}-\mathrm{Pb}$ and $\mathrm{Sn}-$ $\mathrm{Ag}-\mathrm{Cu}$ Solder Interconnects, Journal of ELECTRONIC MATERIALS, 40(10) (2011), 2111-2118 https://doi.org/10.1007/s11664-011-1705-y

9. Hyuntaeck Lim, Pilkyu Kim, Hoemin Jeong, Sungho Jeong, Enhancement of abrasion and corrosion resistance of duplex stainless steel by laser shock peening,
Journal of Materials Processing Technology, 212(6) (2012), 1347-1354 https://doi.org/10.1016/j.jmatprotec.2012.01.023

10. B.Y. Wu, Y.C. Chan, M.O. Alam, Electrochemical corrosion study of Pb-free solders, J. Mater. Res., 21(1) (2006), $62-70$ https://doi.org/10.1557/JMR.2006.0035

11. Corrosion, Vol. 13, 9th Ed., Metals Handbook (ASM) International, Metals Park, $\mathrm{OH}$, (1987)

12. William Stephen Tait, An introduction to electrochemical corrosion testing for practicing and engineers and scientists, 1-55 (1904)

13. M. G. Fontana, Corrosion engineering, McGraw-Hill, 153-218 (1987)

14. G. Montesperelli, M. Rapone, F. Nanni, P. Travaglia, P. Riani, R. Marazza, G. Gusmano, Materials and Corrosion 59(8) (2008), 662-667 https://doi.org/10.1002/maco.20080409

15. Q. V. Bui, N. D. Nam, B. I. Noh, A. Kar, J. G. Kim and S. B. Jung, Effect of Ag addition on the corrosion properties of Sn-based solder alloys, Materials and Corrosion, 61(1) (2010), 30-33 https://doi.org/10.1002/maco.200905237

16. Alberto Torres, Luis Hernandez, Octavio Dominguez, Effect of Antimony Additions on Corrosion and Mechanical Properties of Sn-Bi Eutectic Lead-Free Solder Alloy, Materials Sciences and Applications, (2012), 355-362 https://doi.org/10.4236/msa.2012.36051 